\title{
Auditory sensitivity and vocalizations of the field sparrow (Spizella pusilla)
}

\author{
ROBERT J. DOOLING, SUSAN S. PETERS, and MARGARET H. SEARCY \\ Rockefeller University Field Research Center, Millbrook, New York 12545
}

\begin{abstract}
The auditory sensitivity of the field sparrow (Spizella pusilla) was measured by behavioral audiometry. Two male birds were trained by instrumental avoidance conditioning to respond to pure tones. Thresholds for pure tones between $.25 \mathrm{kHz}$ and $12.0 \mathrm{kHz}$ were measured over a number of days. Auditory sensitivity is greatest between 1.0 and $4.0 \mathrm{kHz}$ and declines about $12 \mathrm{~dB} /$ octave from $2.0 \mathrm{kHz}$ down to $.25 \mathrm{kHz}$ and from $2.0 \mathrm{kHz}$ up to $8.0 \mathrm{kHz}$. Above $8 \mathrm{kHz}$, auditory sensitivity falls off steeply at the rate of about $70 \mathrm{~dB} /$ octave. The range of auditory sensitivity of the field sparrow compares favorably with the range of frequencies found in the vocal repertoire of this species.
\end{abstract}

Comparative studies of hearing in a number of species of birds have revealed several tendencies. First, the peak in the long-term average power spectrum of the species' song coincides with the most sensitive point in the audibility curve (Dooling, Mulligan, \& Miller, 1971; Konishi, 1970). Second, passerines, or song birds, tend to have better sensitivity to high frequencies and poorer sensitivity to low frequencies than nonpasserines (Dooling \& Saunders, 1975; Dooling, Zoloth, \& Baylis, 1978; Hienz, Sinnott, \& Sachs, 1977).

Recently, conditioning procedures along with psychophysical testing methods have been shown to afford a quick and reliable estimate of auditory capability (Dooling \& Saunders, 1975). The present paper extends such methods to the measurement of absolute auditory sensitivity in a song bird, the field sparrow (Spizella pusilla). The field sparrow's auditory sensitivity is discussed in relation to the species' vocalizations and in relation to the hearing sensitivity of other avian species.

\section{METHOD}

\section{Material}

Two male field sparrows served as subjects in this experiment. All testing was done in a sound-deadened booth (IAC 1200 series) in which a loudspeaker was mounted to the ceiling of the chamber. The background noise in this chamber, as measured in octave bands, was below $15 \mathrm{~dB}$ for octave bands with center frequencies above $500 \mathrm{~Hz}$. This is equivalent to a spectrum level less than $-10 \mathrm{~dB}$ across the frequency range of interest and is well below the field sparrow thresholds reported in this paper.

The audiometer, test environment, and sound field calibration procedure are essentially identical to that described earlier (Dooling \& Saunders, 1975; Dooling et al., 1978). The training and testing procedures have also been published in detail (Dooling, 1973; Dooling \& Saunders, 1975). During testing, the birds were restricted in a tube-like device that was mounted a fixed distance of $29 \mathrm{~cm}$ below the speaker. Thus the sound pressure level could be specified at the bird's head.

\section{Procedure}

The birds were trained to avoid shock following the presenta-

We thank W. Searcy and P. Price for valuable comments. This study was supported by NIMH Grant MH14651. tion of a test tone by biting a response bar mounted $2 \mathrm{~cm}$ in front of its bill. A bite response was detected by a high-impedance switch connected between the bird's leg and the response bar, and this response automatically terminated a trial. A pure tone was presented for $5.0 \mathrm{sec}$, and failure to respond during this interval resulted in the pairing of loud white noise and shock with the tone until a response occurred. Shock was delivered in 40-msec pulses to wires wrapped around each of the bird's legs, and the current was kept constant at about $.02 \mathrm{~mA}$. Once the birds were responding reliably to a $2.0 \mathrm{kHz}$ tone at an intensity of about $70 \mathrm{~dB} \mathrm{SPL}$ (re $20 \mu \mathrm{N} / \mathrm{m}^{2}$ ), a modified method-of-limits testing procedure was introduced using a descending series of intensities. After each correct response at a particular frequency, the sound pressure level of the test tone was decreased $10 \mathrm{~dB}$ and another trial was run. This procedure was continued until the bird failed to respond, whereupon the intensity of the tone was raised either 4 or $6 \mathrm{~dB}$ and a final trial was run. Threshold was defined as the sound pressure level halfway between the lowest level resulting in a correct response and the highest level resulting in a failure to respond. This procedure was repeated on a daily basis for 11 test frequencies between $.25 \mathrm{kHz}$ and $12.0 \mathrm{kHz}$ until stable threshold values were obtained at each frequency. Testing was then continued for 12 additional days, with the order of frequencies tested within a daily session randomized. The audibility curves reported in this paper are taken from the mean thresholds collected at each frequency over the last 12 days of testing.

A number of recent studies have demonstrated a correlation between the spectral characteristics of avian vocalizations and auditory sensitivity (Dooling et al., 1971; Dooling \& Saunders, 1975; Konishi, 1970). In an effort to see if a similar relation held for the field sparrow, we obtained a number of recordings of field sparrow vocalizations from local populations. Several characteristics of these vocalizations were measured from sonogram tracings. For comparison with the audibility curves, these songs were converted to power spectral plots with $150-\mathrm{Hz}$ resolution using a PDP-11/10 computer (Zoloth, Miller, \& Dooling, Note 1).

\section{RESULTS}

The average minimum audible levels of pure tones for the two field sparrows in this study are shown in Figure 1 in comparison to audibiltiy curves for three other avian species. The means and standard deviations of these thresholds are given in Table 1. The field sparrow audibility curve shows the characteristically avian pattern of a narrow range of maximum sensitivity 
in the $1-$ to $5-\mathrm{kHz}$ range with a rapid decline in sensitivity at high frequencies. While there is considerable overlap among the audibility curves, the field sparrow is the most sensitive at high frequencies.

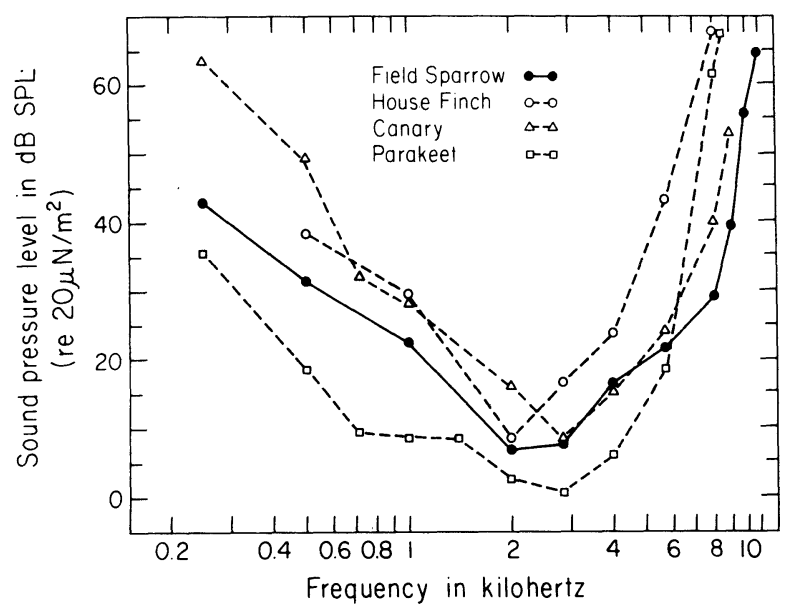

Figure 1. Audibility curve of the field sparrow (Spizella pusilla) compared with the parakeet (Dooling \& Saunders, 1975), canary (Dooling, Mulligan, \& Miller, 1971), and the house finch (Dooling, Zoloth, \& Baylis, 1978).

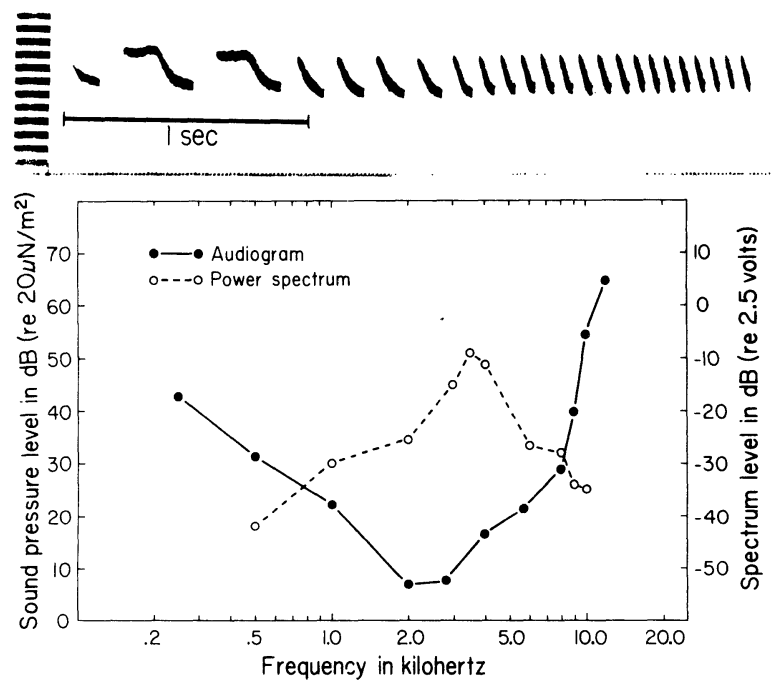

Figure 2. (Top) Sonogram of typical field sparrow song. Time marker equals $1 \mathrm{sec}$. (Bottom) Average power spectrum of two field sparrow songs (dashed lines, open circles) in comparison to the audibility curve (solid lines, closed circles). The audibility curve is referred to the left ordinate and the power spectrum is referred to the right ordinate.
The sonogram of a typical field sparrow vocalization recorded locally is shown in Figure 2 (top). In our recordings, we observed, as did Goldman (1972) and Saunders $(1922,1924)$, that field sparrow songs are relatively simple, with each individual usually singing only one song type. In all, we measured several characteristics of 22 locally recorded field sparrow songs. These songs had a mean length of $2.5 \mathrm{sec}(\mathrm{SD}=.55)$ and were composed of a series of 5 to 38 clear, whistled notes. Duration measurements of 77 note types covered a range of $.5-.05 \mathrm{sec}$.

Our 22 songs spanned a frequency range of 2,200$5,200 \mathrm{~Hz}$, with a mean low frequency of $2,950 \mathrm{~Hz}$ $(S D=261)$ and a mean high frequency of $4,650 \mathrm{~Hz}$ $(S D=210)$. The frequency range of individual note types averaged about $1,200 \mathrm{~Hz}$. The average power spectrum of two field sparrow songs is shown in Figure 2 (bottom) in comparison to the species audibility curve. The correlations between the spectral characteristics of vocalizations and auditory sensitivity demonstrated for other species (Dooling et al., 1971; Konishi, 1970) also hold for the field sparrow.

\section{DISCUSSION}

Audibility curves have been reported for a number of passerine and nonpasserine birds (Dooling et al., 1971; Dooling \& Saunders, 1975; Schwartzkopff, 1955; Trainer, 1946). A review of this literature indicates a general tendency for nonsong birds to show better sensitivity to low frequencies than song birds, with the converse being true for high frequencies. The field sparrow supports this general trend and, in fact, shows much better high-frequency sensitivity than either the house finch or the canary.

As has been demonstrated for a number of avian species, the bandwidth of the audibility curve seems to be tuned to the range of frequencies in the species song. We did not analyze the calls of the field sparrow, but our impressions, as well as those of others (Goldman, 1972), are that some field sparrow calls are extremely high pitched. Dooling et al. (1971) have suggested that songs may be broadcast signals and thus adapted to communication at a distance. Calls are not necessarily adapted to distance communication in song birds and thus may or may not coincide with the region of greatest sensitivity of the audiogram. The relation between auditory sensitivity and vocalizations in the field sparrow fits this general hypothesis.

Playback studies in the field have indicated that individual song recognition is conveyed by subtle acoustic cues (Brooks \& Falls, 1975a, 1975b; Stefanski \& Falls, 1972). Song birds, like the field sparrow, are particularly interesting since they tend to have acoustically complex vocal signals and also share with man the characteristic of vocal learning (Nottebohm, 1972). Perhaps the tendency toward better high-frequency hearing in song birds is related to this complexity in vocal signals.

Table 1

Auditory Thresholds of Two Field Sparrows

\begin{tabular}{llrrrrrrrrrrrr}
\hline & & \multicolumn{10}{c}{ Frequency (Kilohertz) } \\
\cline { 3 - 12 } Bird & & .25 & .50 & 1.00 & 2.00 & 2.86 & 4.00 & 5.70 & 8.00 & 9.00 & 10.0 & 12.0 \\
\hline \multirow{2}{*}{ PI 119 } & Mean & 43.3 & 29.8 & 20.9 & 6.75 & 7.67 & 15.7 & 23.9 & 29.8 & 29.0 & 55.0 & 64.8 \\
& SD & 6.6 & 9.2 & 5.2 & 5.4 & 6.8 & 7.5 & 11.0 & 10.1 & 9.8 & 9.9 & 7.4 \\
OR 114 & Mean & 43.3 & 34.6 & 22.0 & 6.58 & 7.83 & 18.5 & 23.2 & 31.4 & 40.8 & 52.7 & 63.4 \\
& SD & 4.1 & 6.1 & 6.2 & 3.3 & 6.6 & 7.3 & 9.9 & 6.8 & 7.6 & 5.9 \\
\end{tabular}

Note-All values are in decibels (re $\left.20 \mathrm{uN} / \mathrm{m}^{2}\right)$. 


\section{REFERENCE NOTE}

1. Zoloth, S. R., Miller, R., \& Dooling, R. J. A minicomputer system for the synthesis of animal vocalizations. Unpublished manuscript, 1978.

\section{REFERENCES}

Brooks, R. J., \& F ALLS, J. B. Individual recognition by song in white-throated sparrows. I. Discrimination of songs by neighbors and strangers. Canadian Journal of Zoology, 1975, 53, 879-888. (a)

Brooks, R. J., \& FALLs, J. B. Individual recognition by song in white-throated sparrows. III. Song features used in individual recognition. Canadian Journal of Zoology, 1975, 53, 17491761. (b)

Dooling, R. J. Behavioral audiometry with the parakeet (Melopsittacus undulatus). Journal of the Acoustical Society of America, 1973, 53, 1757-1758.

Dooling, R. J., Mulligan, J. A., \& Miller, J. D. Auditory sensitivity and song spectrum of the common canary (Serinus canarius). Journal of the Acoustical Society of America, 1971, 50, 700-709.

Dooling, R. J., \& Saunders, J. C. Hearing in the parakeet (Melopsittacus undulatus): Absolute thresholds, critical ratios, frequency difference limens and vocalizations. Journal of Comparative and Physiological Psychology, 1975, 88, 1-20.

Dooling, R. J., Zoloth, S. R., \& Baylis, J. R. Auditory sen- sitivity, equal loudness, vocalizations and temporal discrimination in the house finch (Carpodacus mexicanus). Journal of Comparative and Physiological Psychology, 1978, 92, 867-876.

Goldman, P. C. The vocal behavior of the field sparrow. Unpublished doctoral thesis, Ohio State University, 1972.

Hienz, R. D., Sinnott, J. M., \& Sachs, M. B. Auditory sensitivity of the red-winged blackbird (Agelaius phoeniceus) and brown-headed cowbird (Molothrus ater). Journal of Comparative and Physiological Psychology, 1977, 91, 1365-1376.

Konishi, M. Comparative neurophysiological studies of hearing and vocalizations in songbirds. Zeitschrift für Tierpsychologie, 1970, 66, 257-272.

Noтte вонм, F. The origins of vocal learning. American Naturalist, 1972, 106, 116-140.

Saunders, A. A. The song of the field sparrow. Auk, 1922, 39, 386-399.

Saunders, A. A. Recognizing individual birds by song. $A u k$, 1924, 41, 242-259.

SchWARTZKopfF, J. On the hearing of birds. $A u k, 1955,72$, 340-347.

Stefanski, R. A., \& Falls, J. B. A study of distress calls of song, swamp, and white-throated sparrows (Aves: Fringillidae). II. Interspecific responses and properties used in recognition. Canadian Journal of Zoology, 1972, 50, 1513-1525.

Traine R, J. E. The auditory acuity of certain birds. Unpublished doctoral dissertation, Cornell University, 1946.

(Received for publication May 3, 1979.) 